\title{
Photoreductive Dissolution of Schwertmannite with Incorporated As(V) Induced by Oxalate and the Mobilization of $A s(V)$
}

\author{
Zhaoyang $\mathrm{Ji}^{1} \cdot$ Haitao $\mathrm{Ren}^{2} \cdot$ Shaoyi Jia ${ }^{1} \cdot$ Songhai Wu${ }^{1}$
}

Received: 21 March 2018 / Revised: 14 May 2018 / Accepted: 22 May 2018 / Published online: 16 June 2018

(c) The Author(s) 2018

\begin{abstract}
Schwertmannite (Sh), a poorly crystalline iron (hydr)oxide that usually appears in acid mine drainage, plays a significant role in the immobilization of $\mathrm{As}(\mathrm{V})$. In this study, the effects of UV irradiation and oxalate on the dissolution of Sh with structurally incorporated $\mathrm{As}(\mathrm{V})[\mathrm{Sh}-\mathrm{As}(\mathrm{V})]$ and the subsequent mobilization of $\mathrm{As}(\mathrm{V})$ were investigated at $\mathrm{pH}$ 3.0. In the dark, more total dissolved Fe was produced (the maximum value was $33.2 \mathrm{mg} / \mathrm{L}$ ) in the suspensions of $\mathrm{Sh}-\mathrm{As}(\mathrm{V})$ with oxalate than in those without oxalate. UV irradiation slightly enhanced the mobilization of As(V) for the system of Sh-As(V)-1 and $\mathrm{Sh}-\mathrm{As}(\mathrm{V})-2$ in the absence of oxalate compared with that in the dark. However, in the presence of oxalate, UV irradiation caused the concentration of mobilized As(V) to decline by 630-875\% compared with that in the dark. This study enhanced our understanding of the mobilization of $\mathrm{As}(\mathrm{V})$ and demonstrated that $\mathrm{UV}$ irradiation could contribute to the immobilization of $\mathrm{As}(\mathrm{V})$ on $\mathrm{Sh}$ in aqueous environments containing oxalate.
\end{abstract}

Keywords Schwertmannite $\cdot$ Photoreductive dissolution $\cdot$ Oxalate $\cdot$ As $(V) \cdot$ Mobilization

\section{Introduction}

Arsenic (As) is a toxic contaminant that is mainly present in inorganic forms as oxyanions of trivalent arsenite [As(III)] or pentavalent arsenate $[\mathrm{As}(\mathrm{V})]$ in aqueous environments [1]. Various health issues including skin lesions, circulatory disorders, and diverse cancers are correlated with longterm intake of water with arsenic [2,3]. Considering the severe toxicity of arsenic, the World Health Organization reduced the guideline for arsenic in drinking water from 50 to $10 \mu \mathrm{g} / \mathrm{L}$ in 1993 [4]. The existence of arsenic in drinking water results from the dissolution of As-bearing minerals, microbial activities, geochemical reactions, and drainage of As-rich sewage generated from anthropogenic activities such as agriculture, metallurgy, and mining [1,5].

Iron (hydr)oxides are found in natural environments as an impressive array of minerals, most commonly goethite

Songhai $\mathrm{Wu}$

wusonghaitjuedu@163.com

1 School of Chemical Engineering and Technology, Tianjin University, Tianjin 300350, China

2 State Key Laboratory of Separation Membranes and Membrane Processes, School of Textiles, Tianjin Polytechnic University, Tianjin 300387, China
$(\alpha-\mathrm{FeOOH})$, ferrihydrite $\left(\mathrm{Fe}_{5} \mathrm{HO}_{8} \cdot 4 \mathrm{H}_{2} \mathrm{O}\right)$, lepidocrocite $(\gamma-\mathrm{FeOOH})$, and schwertmannite $\left[\mathrm{Sh} ; \mathrm{Fe}_{8} \mathrm{O}_{8}(\mathrm{OH})_{8-2 x}\left(\mathrm{SO}_{4}\right)_{x}\right.$, $1.0 \leq x \leq 1.85][6,7]$. On account of their natural abundance and surface absorptivity, iron (hydr)oxides play a significant role in attenuating the concentration of arsenic in natural environments through adsorption and precipitation. As a result, dissolution of iron (hydr)oxides is of great importance to the mobilization of arsenic.

Sunlight irradiation can lead to the light-induced dissolution of iron (hydr)oxides in photic water and soil surface [8-12]. Two reaction steps are involved in this photoreductive dissolution process: (1) photoreduction of Fe(III) on the surface of iron (hydr)oxides and (2) subsequent release of surface-bound Fe(II) into solution [9]. Previous studies demonstrated that two mechanisms are known to potentially account for the formation of surface $\mathrm{Fe}$ (II) in natural water: (1) Electrons and holes are generated under irradiation via the charge transfer between lattice $\mathrm{O}^{-2}$ and $\mathrm{Fe}(\mathrm{III})$ in iron (hydr)oxides, and photo-induced electrons will result in surface $\mathrm{Fe}(\mathrm{III})$ reduction (i.e., the mechanism of semiconductor); (2) ligand-to-metal charge transfer in $\mathrm{Fe}(\mathrm{III})$ complexes formed on photoactive surface contributes to the formation of surface Fe(II) [9]. Dissolved organic matter can effectively promote the reductive dissolution of iron minerals containing arsenic [9-12]. Siderophores [desferrioxamine 
B (DFOB) and aerobactin] can accelerate the light-induced dissolution of lepidocrocite. Lepidocrocite dissolves 91 times faster in the presence than in the absence of DFOB at $\mathrm{pH} 3$ [12].

Oxalate (concentration varies from $2.5 \times 10^{-5}$ to $4.0 \times 10^{-3} \mathrm{~mol} / \mathrm{L}$ ) is usually detected in natural waters. Meanwhile, oxalate has a remarkable contribution to the dissolution of iron (hydr)oxides [13]. During the past decade, intensive studies of irradiated iron (hydr)oxide-oxalate systems, which exist in natural aqueous environments and on soil surface, have been carried out. Many kinds of environmental pollutants can be degraded in such systems due to the photo-Fenton-like reaction [14-18]. Wu et al. [18] revealed that $5 \mathrm{~min}$ of UV irradiation yields $25 \mathrm{mg} / \mathrm{L}$ dissolved $\mathrm{Fe}(\mathrm{II})$ in the system of schwertmannite $(1 \mathrm{~g} / \mathrm{L})$ and oxalate $(4.4 \mathrm{mmol} / \mathrm{L})$ at $\mathrm{pH} 4.0$. In addition, $97 \%$ of methyl orange with the initial concentration of $50 \mathrm{mg} / \mathrm{L}$ can be removed after 40 min of UV irradiation.

Nevertheless, studies related to the photochemical reactions of the ternary $\mathrm{As}(\mathrm{V})$-iron (hydr)oxide-oxalate system are limited. Under light illumination, the effects of oxalate on the mobilization of $\mathrm{As}(\mathrm{V})$, which is adsorbed onto and structurally incorporated into iron minerals, have not been studied. Moreover, the mechanism involved in the immobilization of the released $\mathrm{As}(\mathrm{V})$ by residual minerals or newly formed secondary iron minerals is not clearly understood.

Acid mine drainage (AMD) involves polluted water with low $\mathrm{pH}$ and high concentrations of heavy metals and other toxic elements [19]. Nordstrom et al. [20] reported that the $\mathrm{As}(\mathrm{V})$ concentration can reach $850 \mathrm{mg} / \mathrm{L}$ in an acid seep at Iron Mountain, California. Sh is a poorly crystalline metastable mineral that usually appears in AMD. [21, 22]. Sh can immobilize a large amount of $\mathrm{As}(\mathrm{V})$ [23]. Our recent study suggested distinctions in reactivity between Sh with adsorbed As(V) $\left[\mathrm{Sh}^{*}-\mathrm{As}(\mathrm{V})\right]$ and Sh with structurally incorporated $\mathrm{As}(\mathrm{V})[\mathrm{Sh}-\mathrm{As}(\mathrm{V})][24]$. The present research focused on the photochemical reactions of the ternary $\mathrm{As}(\mathrm{V})-\mathrm{Sh}-$ oxalate system. We aimed to investigate the effect of oxalate and the amount of structurally incorporated $\mathrm{As}(\mathrm{V})$ on photoreductive dissolution of $\mathrm{Sh}-\mathrm{As}(\mathrm{V})$ and the mobilization of $\mathrm{As}(\mathrm{V})$ involved in this process.

\section{Experimental Section}

\section{Materials}

All laboratory glassware was repeatedly rinsed with deionized water before use. $\mathrm{NaH}_{2} \mathrm{AsO}_{4} \cdot 7 \mathrm{H}_{2} \mathrm{O}$ (Merck, purity $>99.0 \%$ ) and oxalate (Tianjin Bodi Chemical Co., Ltd., Tianjin, China, purity $>98.0 \%)$ were used as As(V) and oxalate sources, respectively.

\section{Synthesis of Sh and Sh-As(V)}

Sh was prepared following the procedures reported by Loan et al. [25]. In this method, preheated deionized water $(500 \mathrm{~mL})$ was mixed with $\mathrm{Fe}_{2}\left(\mathrm{SO}_{4}\right)_{3}(2.6 \mathrm{~g})$ in a roundbottomed flask with a mechanical stirrer. The flask was then placed in a water bath at $85^{\circ} \mathrm{C}$ for $1 \mathrm{~h}$.

The process of preparing $\mathrm{Sh}-\mathrm{As}(\mathrm{V})$ by the co-precipitation method was basically the same as that of preparing $\mathrm{Sh}$. However, a certain amount of $\mathrm{As}(\mathrm{V})$ was added to the water in advance and warmed up to $85^{\circ} \mathrm{C}$, and the reaction time was $2 \mathrm{~h}$. After the suspension cooled to room temperature, it was centrifuged at $4200 \mathrm{r} / \mathrm{min}$ for $5 \mathrm{~min}$. The obtained solid was washed with distilled water for three times and then freeze-dried.

The contents of $\mathrm{As}(\mathrm{V})$ in the synthetic $\mathrm{Sh}-\mathrm{As}(\mathrm{V})$ were determined by the following methods. First, $0.015 \mathrm{~g}$ of $\mathrm{Sh}-\mathrm{As}(\mathrm{V})$ solid was dispersed in $150 \mathrm{~mL}$ of $\mathrm{NaCl}$ solution $(0.1 \mathrm{~mol} / \mathrm{L})$ at $\mathrm{pH} 3.0$. Second, $0.264 \mathrm{~g}$ of ascorbic acid was added to the mixture. The suspension was electromagnetically stirred for $24 \mathrm{~h}$ to guarantee that $\mathrm{Sh}-\mathrm{As}(\mathrm{V})$ was completely dissolved. After the dissolution reaction, the suspension was centrifuged at 12,000 r/min for $5 \mathrm{~min}$, and the supernatant was used to determine the As(V) concentration.

\section{Photochemical Experiment}

(Photo)dissolution experiments were carried out in an XPA-7 photochemical reactor (Xujiang Electromechanical Plant, Nanjing, China). A 300-W Hg lamp was used as the light source. The wavelength was mainly $365 \mathrm{~nm}$, and the power was $2.5 \mathrm{~mW} / \mathrm{cm}^{2}$. Before the experiments, the lamp was turned on for $5 \mathrm{~min}$ to guarantee stable irradiating intensity during the experiment period. Sh-As(V) was dispersed in $15 \mathrm{~mL} \mathrm{NaCl}$ solution $(0.1 \mathrm{~mol} / \mathrm{L})$ at $\mathrm{pH}$ 3.0. In Sh-As(V) dissolution, $2 \mathrm{mmol} / \mathrm{L}$ oxalate in $15 \mathrm{~mL}$ $\mathrm{NaCl}$ solution $(0.1 \mathrm{~mol} / \mathrm{L})$ with the same $\mathrm{pH}$ was mixed with the Sh-As(V) suspension. After mixing, the initial concentrations of $\mathrm{Sh}-\mathrm{As}(\mathrm{V})$ and oxalate were $0.1 \mathrm{~g} / \mathrm{L}$ and $1 \mathrm{mmol} / \mathrm{L}$, respectively. During the photoreactions, the suspensions were stirred with a magnetic stirrer at $800 \mathrm{r} /$ min. A steady flow of cooling water was used to maintain a constant temperature of about $25 \pm 1{ }^{\circ} \mathrm{C}$. In addition, photodissolution experiments of $\mathrm{Sh}-\mathrm{As}(\mathrm{V})$ in the absence of oxalate were carried out for comparison. In the duration of the dissolution experiments, solution samples of $1.0 \mathrm{~mL}$ were pipetted every $30 \mathrm{~min}$ and centrifuged at 12,000 r/ $\min$ for $5 \mathrm{~min}$. The supernatant was applied to determine the concentrations of $\mathrm{As}(\mathrm{V})$, dissolved $\mathrm{Fe}(\mathrm{II})$, and total $\mathrm{Fe}$. Experiments in the dark were conducted at the same 
conditions. All the experiments in this section were conducted in duplicate, and the average values were recorded.

\section{Analytical Methods}

The As(V) concentration was detected by a molybdate blue method [26], and the detection limit for $\mathrm{As}(\mathrm{V})$ in this study was $0.005 \mathrm{mg} / \mathrm{L}$. Dissolved Fe(II) concentration was detected by a modified ferrozine method. To eliminate the interference of $\mathrm{Fe}(\mathrm{III}), 0.05 \mathrm{~mol} / \mathrm{L} \mathrm{NaF}$ was added to mask $\mathrm{Fe}(\mathrm{III})$ in $\mathrm{Fe}$ (II) determination. The total dissolved $\mathrm{Fe}$ was determined by reducing total $\mathrm{Fe}(\mathrm{III})$ to $\mathrm{Fe}(\mathrm{II})$, and dissolved $\mathrm{Fe}$ (II) was measured by the ferrozine method without the addition of $\mathrm{NaF}$ solution [27]. We demonstrated the phase composition of iron (hydr)oxides by applying X-ray diffraction (XRD, Rigaku D/max 2200/PC). The Fourier transform infrared (FTIR, Nicolet 670, Thermo Fisher Scientific) spectrum was utilized to determine the variety of iron (hydr)oxides.

\section{Results and Discussion}

\section{Characterization of Synthetic Sh-As(V)}

In this study, $\mathrm{Sh}-\mathrm{As}(\mathrm{V})-i(i=1,2$, or 3$)$ represented $\mathrm{Sh}$ with various amounts of structurally incorporated $\mathrm{As}(\mathrm{V})$. Specifically, the amount of structurally incorporated $\mathrm{As}(\mathrm{V})$ was $142.0,128.0$, and $64.0 \mathrm{mg} / \mathrm{g}$ for $\mathrm{Sh}-\mathrm{As}(\mathrm{V})-1$, Sh-As(V)-2, and Sh-As(V)-3, respectively (Table 1).

Figure 1 shows the XRD pattern of synthetic Sh, in which all diffraction peaks were in accordance with rhomb-centered hexagonal Sh (JCPDS Card No. 47-1775). Specifically, the diffraction peaks at $2 \theta$ of $26.3^{\circ}, 35.2^{\circ}$, and $61.3^{\circ}$ were indexed to be (310), (212), and (004) planes of pure Sh, respectively [22]. XRD patterns of Sh-As(V) were similar to those of Sh (data not shown).

FTIR analyses of Sh-As(V) are shown in Fig. 2. The peak at $825 \mathrm{~cm}^{-1}$ was assigned to the As-O stretching vibration of As-O-Fe coordination [28].

Table 1 Content of structurally incorporated $\mathrm{As}(\mathrm{V})$ into $\mathrm{Sh}$

\section{Effect of UV Irradiation on the Mobilization of As(V) in $\mathrm{Sh}-\mathrm{As}(\mathrm{V})$ in the Absence of Oxalate}

Figure 3 shows the concentrations of total dissolved $\mathrm{Fe}$ and $\mathrm{Fe}(\mathrm{II})$ during the dissolution of $\mathrm{Sh}-\mathrm{As}(\mathrm{V})$ in the absence of oxalate in the dark. Total dissolved $\mathrm{Fe}$ increased slightly and leveled off at $1.66,2.11$, and $4.23 \mathrm{mg} / \mathrm{L}$ after $120 \mathrm{~min}$ for Sh-As(V)-1, Sh-As(V)-2, and Sh-As(V)-3, respectively (Fig. 3a). Under UV irradiation, the total dissolved Fe continued to increase during the whole experimental period (Fig. 4a). After $240 \mathrm{~min}$, dissolution of Sh-As(V) resulted in $4.98,5.43$, and $7.85 \mathrm{mg} / \mathrm{L}$ total dissolved $\mathrm{Fe}$, and these values were nearly double of the amounts in the dark (Fig. 4a). In addition, the vast majority of them was dissolved Fe(II) (Fig. 4b). This result indicated that the photoreductive dissolution of Sh-As $(\mathrm{V})$ could proceed in the absence of organic ligands under acidic condition. A previous study demonstrated that $6 \mathrm{~h}$ of UV irradiation of lepidocrocite suspensions $(25 \mathrm{mg} / \mathrm{L})$ at $\mathrm{pH} 3.0$ in the absence of organic ligands resulted in the formation of $6.13 \mu \mathrm{mol} / \mathrm{L}$ total dissolved Fe, and $90 \%$ of them presented as Fe(II) [11].

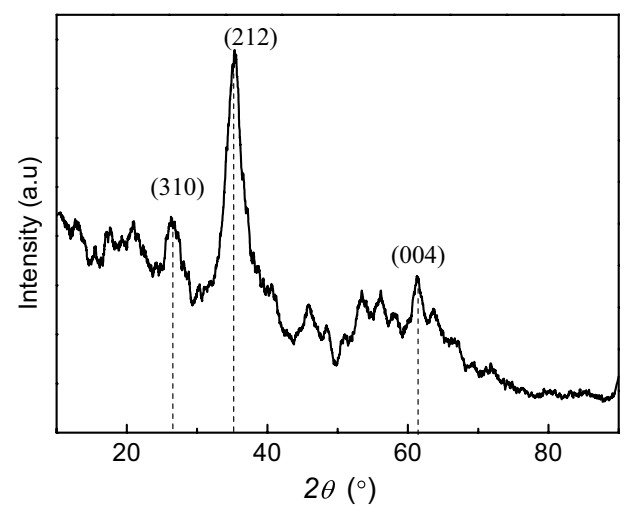

Fig. 1 XRD pattern of the synthetic schwertmannite (Sh)

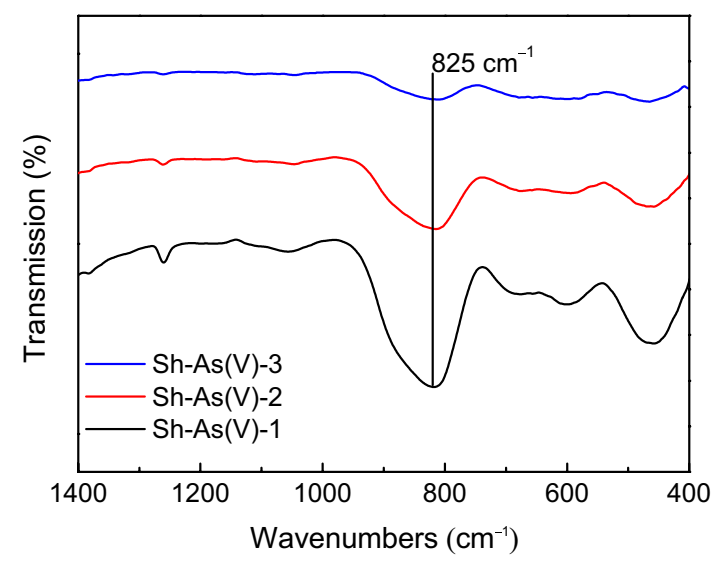

Fig. 2 FTIR analyses of Sh-As(V) 

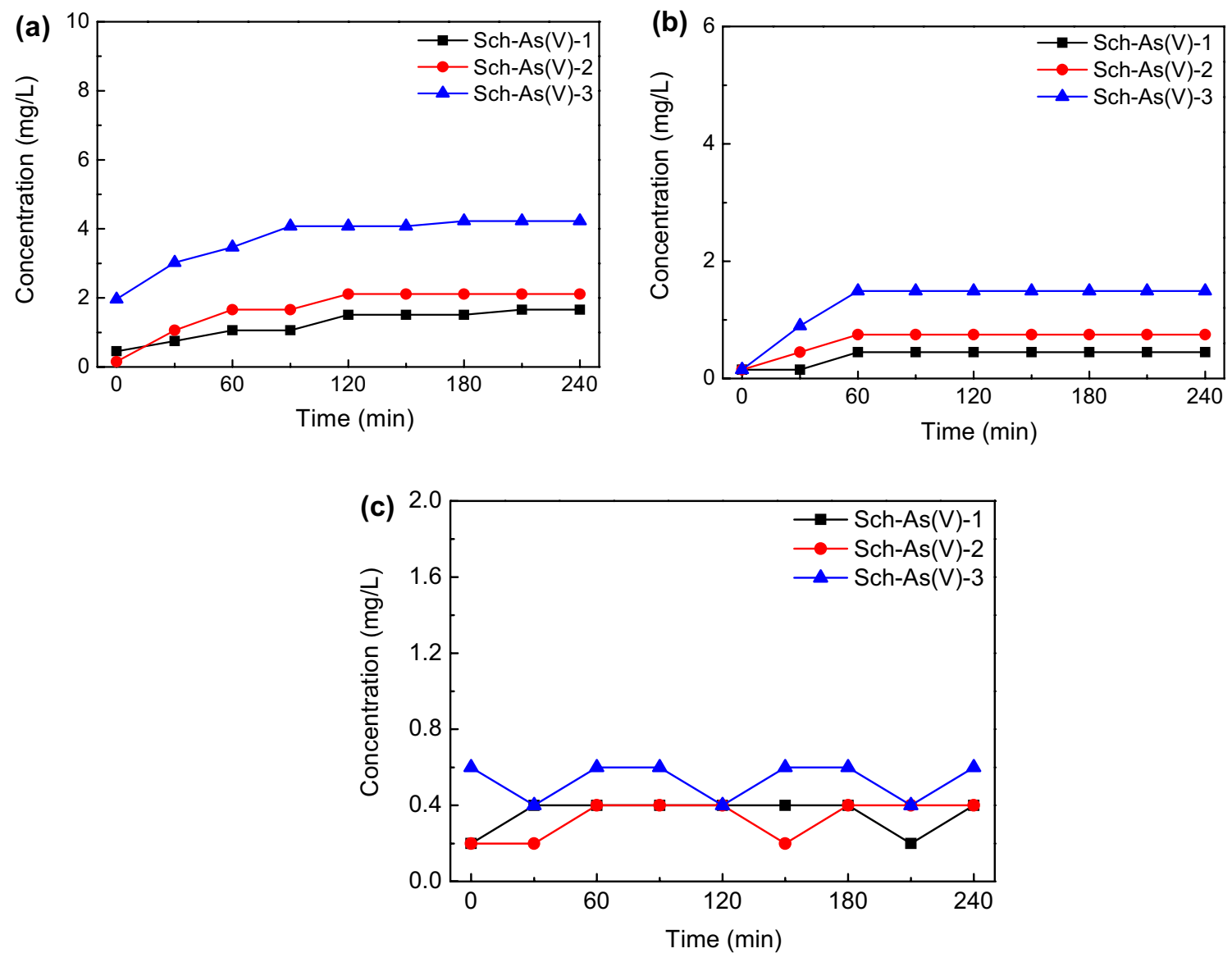

Fig. 3 Dissolution experiments in the dark with suspensions of $0.1 \mathrm{~g} / \mathrm{L} \mathrm{Sh}-\mathrm{As}(\mathrm{V})$ at $\mathrm{pH} 3.0$ and $0.1 \mathrm{~mol} / \mathrm{L}$ ionic strength $(\mathrm{NaCl})$ in the absence of oxalate. a total dissolved $\mathrm{Fe}, \mathbf{b}$ dissolved $\mathrm{Fe}(\mathrm{II})$, and $\mathbf{c} \mathrm{As}(\mathrm{V})$ were measured

In the absence of oxalate, the mobilization of $\mathrm{As}(\mathrm{V})$ during the dissolution of $\mathrm{Sh}-\mathrm{As}(\mathrm{V})$ in the dark and under UV irradiation is shown in Figs. 3c and 4c, respectively. In the dark, the concentration of $\mathrm{As}(\mathrm{V})$ varied slightly at $0.4,0.4$, and $0.6 \mathrm{mg} / \mathrm{L}$ for $\mathrm{Sh}-\mathrm{As}(\mathrm{V})-1, \mathrm{Sh}-\mathrm{As}(\mathrm{V})-2$, and $\mathrm{Sh}-\mathrm{As}(\mathrm{V})-3$, respectively (Fig. 3c). Under UV irradiation, the final concentration of aqueous $\mathrm{As}(\mathrm{V})$ declined apparently with the decrease in the $\mathrm{As}(\mathrm{V})$ content in $\mathrm{Sh}-\mathrm{As}(\mathrm{V})$, which was $1.4,0.8$, and $0.6 \mathrm{mg} / \mathrm{L}$ for $\mathrm{Sh}-\mathrm{As}(\mathrm{V})-1, \mathrm{Sh}-\mathrm{As}(\mathrm{V})-2$, and Sh-As(V)-3, respectively (Fig. 4c). Compared with the results in the dark, UV irradiation enhanced the mobilization of $\mathrm{As}(\mathrm{V})$ for the systems of Sh-As(V)-1 and Sh-As(V)-2 in the absence of oxalate. However, the final concentration of aqueous $\mathrm{As}(\mathrm{V})$ was equal in the dark and under UV irradiation for $\mathrm{Sh}-\mathrm{As}(\mathrm{V})-3$, even though more minerals dissolved under UV irradiation.

\section{Effect of UV Irradiation on the Mobilization of As(V) in Sh-As(V) in the Presence of Oxalate}

Dissolution experiments of $\mathrm{Sh}-\mathrm{As}(\mathrm{V})$ in the presence of oxalate showed a significant formation of total dissolved $\mathrm{Fe}$
(Figs. 5, 6). As oxalate mixed with $\mathrm{Sh}-\mathrm{As}(\mathrm{V})$, the total dissolved Fe reached 4.98, 2.86, and $13.73 \mathrm{mg} / \mathrm{L}$ for $\mathrm{Sh}-\mathrm{As}(\mathrm{V})$ 1, Sh-As(V)-2, and Sh-As(V)-3, respectively (Fig. 5a). These results demonstrated that the dissolution reaction of oxalate with $\mathrm{Sh}-\mathrm{As}(\mathrm{V})$ was fast [18]. When the suspensions were in the dark, two stages were found in the variation in total dissolved Fe: A rapid increase was observed within the first $30 \mathrm{~min}$, and the curves leveled off after $90 \mathrm{~min}$ (Fig. 5a). In the presence of oxalate, the dissolution of all three $\mathrm{Sh}-\mathrm{As}(\mathrm{V})$ samples resulted in highly similar total dissolved Fe concentrations ( $32.95 \mathrm{mg} / \mathrm{L}$ ) (Fig. 5a). Therefore, in the dark, the differences in amount of structurally incorporated $\mathrm{As}(\mathrm{V})$ had almost no effect on the dissolution of $\mathrm{Sh}-\mathrm{As}(\mathrm{V})$ in the presence of oxalate.

However, for experiments under UV irradiation, the total dissolved Fe exhibited different trends (Fig. 6a). When the amount of structurally incorporated $\mathrm{As}(\mathrm{V})$ was relatively low [for $\mathrm{Sh}-\mathrm{As}(\mathrm{V})-3$ ], the total dissolved Fe initially decreased and leveled off at $5.73 \mathrm{mg} / \mathrm{L}$ after $60 \mathrm{~min}$ of UV irradiation. However, when the amounts of structurally incorporated $\mathrm{As}(\mathrm{V})$ were high, such as $\mathrm{Sh}-\mathrm{As}(\mathrm{V})-1$ and $\mathrm{Sh}-\mathrm{As}(\mathrm{V})-2$ in the present study (Fig. 6a), the total 

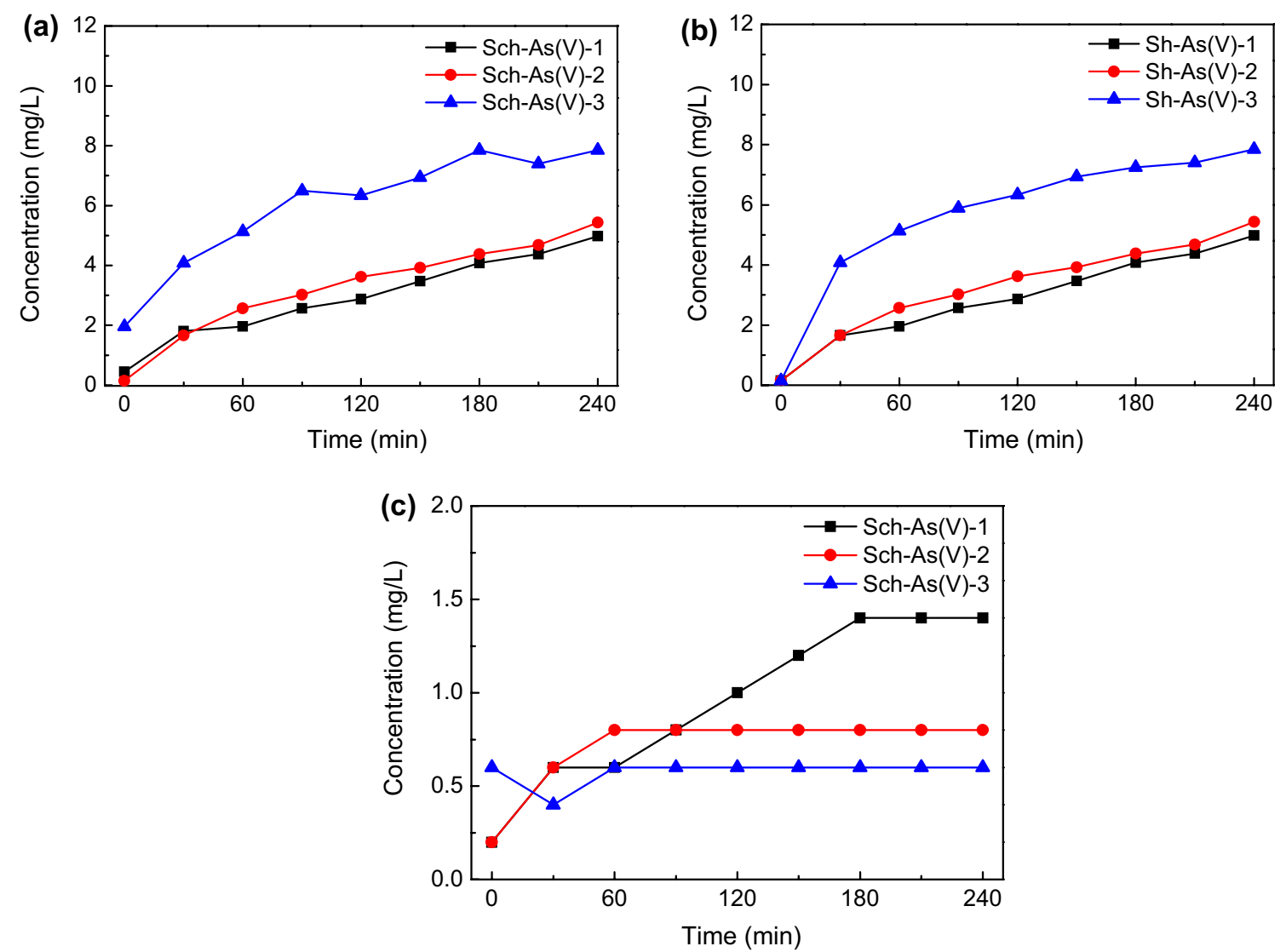

Fig. 4 Dissolution experiments under UV irradiation with suspensions of $0.1 \mathrm{~g} / \mathrm{L} \mathrm{Sh}-\mathrm{As}(\mathrm{V})$ at $\mathrm{pH} 3.0$ and $0.1 \mathrm{~mol} / \mathrm{L}$ ionic strength $(\mathrm{NaCl})$ in the absence of oxalate. a total dissolved Fe, b dissolved Fe(II), and $\mathbf{c} \mathrm{As}(\mathrm{V})$ were measured

dissolved Fe initially increased and peaked within the first $30 \mathrm{~min}$. Subsequently, they decreased and leveled off at 4.22 and $2.87 \mathrm{mg} / \mathrm{L}$ for $\mathrm{Sh}-\mathrm{As}(\mathrm{V})-1$ and $\mathrm{Sh}-\mathrm{As}(\mathrm{V})-2$, respectively (Fig. 6a). After $240 \mathrm{~min}$ of UV irradiation, $\mathrm{pH}$ of the suspensions increased from 3.0 to 6.0. Lan et al. [14] reported that the dissolved $\mathrm{Fe}(\mathrm{III}) / \mathrm{Fe}$ (II) significantly declines in irradiated goethite/oxalate systems. This observation was also attributed to the quick rise in $\mathrm{pH}$ from 3.5 to 6.0 .

The mobilization of As(V) during the dissolution of $\mathrm{Sh}-\mathrm{As}(\mathrm{V})$ in the dark and under UV irradiation in the presence of oxalate is shown in Figs. 5c and 6c, respectively. In the dark, $\mathrm{As}(\mathrm{V})$ increased within the first $60 \mathrm{~min}$ and then leveled off at $12.6,10.8$, and $7.0 \mathrm{mg} / \mathrm{L}$ for Sh-As(V)-1, Sh-As(V)-2, and Sh-As(V)-3, respectively (Fig. 5c). Under UV irradiation, As(V) released from the dissolution of $\mathrm{Sh}-\mathrm{As}(\mathrm{V})$ reached the maximum values after the addition of oxalate, decreased within the first $60 \mathrm{~min}$, and leveled off at 2.0,1.4, and $0.8 \mathrm{mg} / \mathrm{L}$ for Sh-As(V)-1, Sh-As(V)-2, and Sh-As(V)-3, respectively (Fig. 6c).

\section{Proposed Mechanism of Sh-As(V) Dissolution and $\mathbf{A s}(\mathbf{V})$ Mobilization}

On the basis of the above discussion and previous studies $[10,14-16]$, the possible mechanisms of $\mathrm{Sh}-\mathrm{As}(\mathrm{V})$ dissolution induced by oxalate and $\mathrm{As}(\mathrm{V})$ mobilization in the absence and presence of UV irradiation were proposed (Scheme 1). Iron oxide-oxalate complexes of $\left[\equiv \mathrm{Fe}^{\mathrm{III}}\left(\mathrm{C}_{2} \mathrm{O}_{4}\right)_{n}\right]^{(2 n-3)-}$ are formed by the adsorption of oxalate on the surface of $\mathrm{Sh}-\mathrm{As}(\mathrm{V})$ [Eq. (1)]. The symbol $\equiv$ is a shorthand notation of the surface lattice of an $\mathrm{Fe}(\mathrm{III})$ (hydr)oxide. Under UV irradiation, $\left[\equiv \mathrm{Fe}^{\mathrm{III}}\left(\mathrm{C}_{2} \mathrm{O}_{4}\right)_{n}\right]^{(2 n-3)-}$ was excited to form $\left[\equiv \mathrm{Fe}^{\mathrm{II}}\left(\mathrm{C}_{2} \mathrm{O}_{4}\right)_{(n-1)}\right]^{4-2 n}$ and a series of radicals including oxalate radical $\left(\mathrm{C}_{2} \mathrm{O}_{4}\right)^{--}$, carbon-centered radical $\left(\mathrm{CO}_{2}\right)^{--}$, and superoxide ion $\mathrm{O}_{2}^{--}$[Eqs. (2)-(4)]. $\mathrm{Fe}^{3+}$ reacted with $\mathrm{O}_{2}^{--}$to form $\mathrm{O}_{2}$ and $\mathrm{Fe}^{2+}$ [Eq. (5)]. Reduction of Fe(III) could also occur in the solution under UV irradiation according to Eq. (6). In the dark, accompanied with the dissolution of $\mathrm{Sh}-\mathrm{As}(\mathrm{V})$ in the presence of oxalate, structurally incorporated $\mathrm{As}(\mathrm{V})$ was released into the solution. [The maximum concentration of dissolved $\mathrm{As}(\mathrm{V})$ was $12.6 \mathrm{mg} / \mathrm{L}$ 

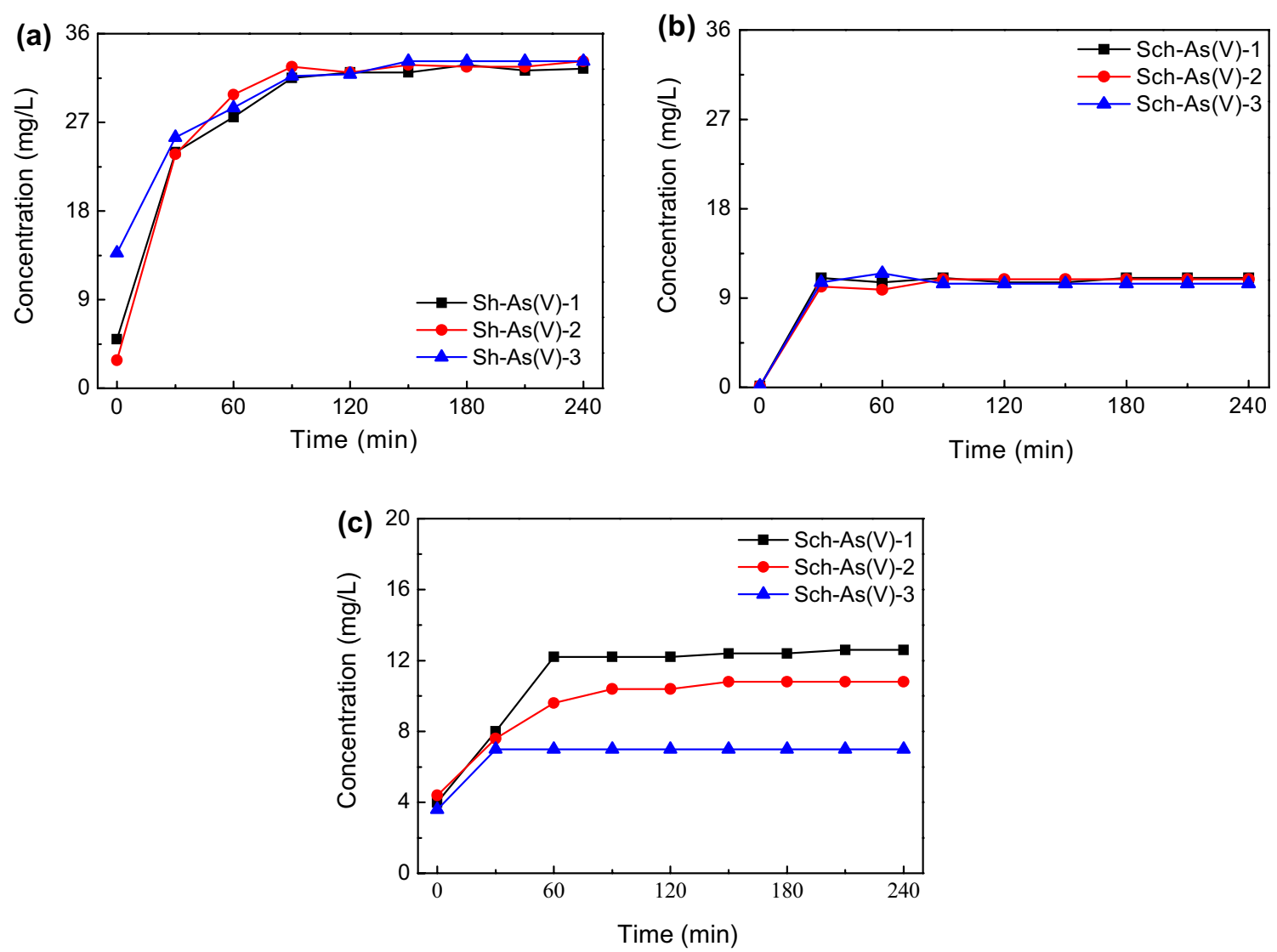

Fig. 5 Dissolution experiments in the dark with suspensions of $0.1 \mathrm{~g} / \mathrm{L} \mathrm{Sh}-\mathrm{As}(\mathrm{V})$ at pH 3.0 and $0.1 \mathrm{~mol} / \mathrm{L}$ ionic strength $(\mathrm{NaCl})$ in the presence of oxalate. a total dissolved $\mathrm{Fe}, \mathbf{b}$ dissolved $\mathrm{Fe}(\mathrm{II})$, and $\mathbf{c} \mathrm{As}(\mathrm{V})$ were measured

(Fig. 5c).] However, under UV irradiation, the mobilization of $\mathrm{As}(\mathrm{V})$ in the system of $\mathrm{Sh}-\mathrm{As}(\mathrm{V})$ was hindered. At the end of the dissolution experiment, the maximum concentration of dissolved As(V) was $2.0 \mathrm{mg} / \mathrm{L}$ (Fig. 6c)], which could be attributed to the re-adsorption of the released $\mathrm{As}(\mathrm{V})$ on residual Sh.

$$
\begin{aligned}
& \mathrm{Sh}+n \mathrm{H}_{2} \mathrm{C}_{2} \mathrm{O}_{4} \leftrightarrow\left[\equiv \mathrm{Fe}^{\mathrm{III}}\left(\mathrm{C}_{2} \mathrm{O}_{4}\right)_{n}\right]^{(2 n-3)-}, \\
& {\left[\equiv \mathrm{Fe}^{\mathrm{III}}\left(\mathrm{C}_{2} \mathrm{O}_{4}\right)_{n}\right]^{(2 n-3)-}+h v \rightarrow\left[\equiv \mathrm{Fe}^{\mathrm{II}}\left(\mathrm{C}_{2} \mathrm{O}_{4}\right)_{(n-1)}\right]^{4-2 n}+\mathrm{C}_{2} \mathrm{O}_{4}^{--},}
\end{aligned}
$$

$\mathrm{C}_{2} \mathrm{O}_{4}^{--} \rightarrow \mathrm{CO}_{2}+\mathrm{CO}_{2}^{--}$,

$\mathrm{CO}_{2}^{--}+\mathrm{O}_{2} \rightarrow \mathrm{CO}_{2}+\mathrm{O}_{2}^{--}$,

$\mathrm{O}_{2}^{--}+\mathrm{Fe}^{3+} \rightarrow \mathrm{Fe}^{2+}+\mathrm{O}_{2}$,
$\left[\mathrm{Fe}^{\mathrm{III}}\left(\mathrm{C}_{2} \mathrm{O}_{4}\right)_{n}\right]^{3-2 n}+h v \rightarrow\left[\mathrm{Fe}^{\mathrm{II}}\left(\mathrm{C}_{2} \mathrm{O}_{4}\right)_{(n-1)}\right]^{4-2 n}+\mathrm{C}_{2} \mathrm{O}_{4}^{--} \cdot$

\section{Conclusions}

This study revealed the effects of UV irradiation and oxalate on the dissolution of $\mathrm{Sh}-\mathrm{As}(\mathrm{V})$. Under UV irradiation, $\mathrm{Fe}$ (III) oxalate complexes formed at the surface of $\mathrm{Sh}-\mathrm{As}(\mathrm{V})$ could be converted into Fe(II) oxalate. UV irradiation slightly enhanced the mobilization of $\mathrm{As}(\mathrm{V})$ for the systems of Sh-As(V)-1 and Sh-As(V)-2 in the absence of oxalate compared with that in the dark. However, in the presence of oxalate, UV irradiation caused the released As(V) to decline by $630-875 \%$ compared with that in the dark. This study enhanced our understanding of As(V) 

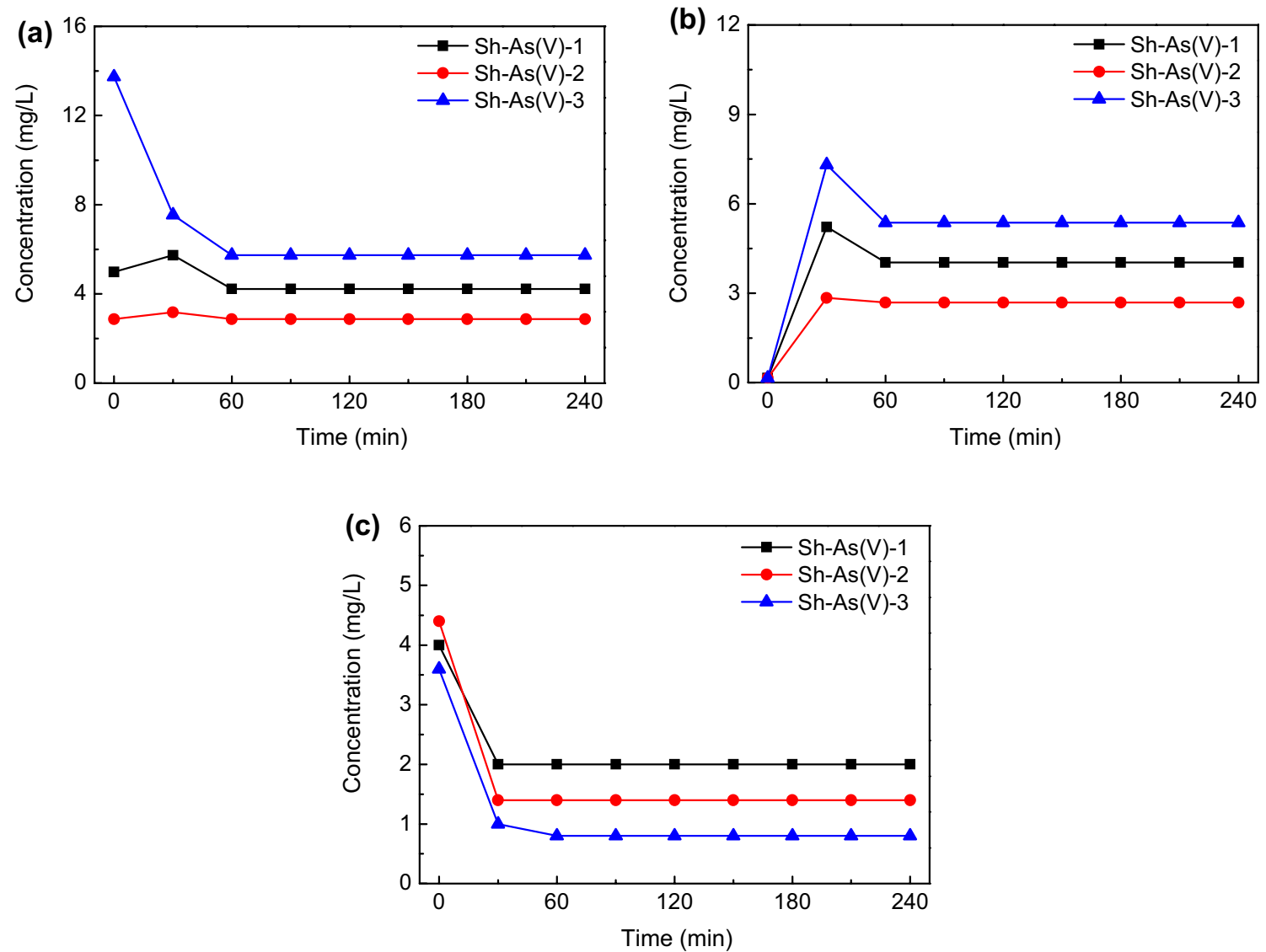

Fig. 6 Dissolution experiments under UV irradiation with suspensions of $0.1 \mathrm{~g} / \mathrm{L} \mathrm{Sh}-\mathrm{As}(\mathrm{V})$ at $\mathrm{pH} 3.0$ and $0.1 \mathrm{~mol} / \mathrm{L}$ ionic strength $(\mathrm{NaCl})$ in the presence of oxalate. a total dissolved $\mathrm{Fe}, \mathbf{b}$ dissolved $\mathrm{Fe}(\mathrm{II})$, and $\mathbf{c} \mathrm{As}(\mathrm{V})$ were measured

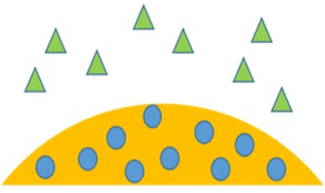

Sh-As(V)

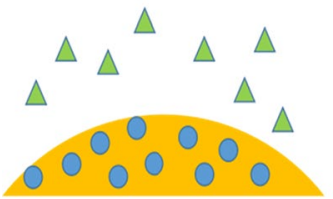

Sh-As(V)

$\triangle$ oxalate

$\operatorname{As}(\mathrm{V})$
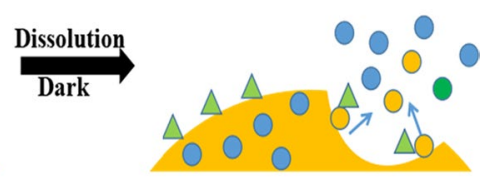

Sh-As(V)

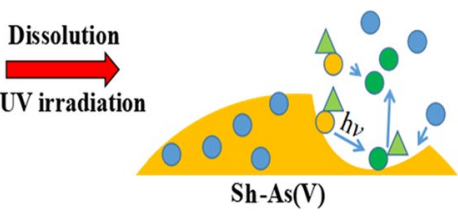

$\bigcirc \mathrm{Fe}(\mathrm{III})$

$\mathrm{Fe}(\mathrm{II})$
Scheme 1 Proposed mechanisms of Sh dissolution and As(V) mobilization in $\mathrm{Sh}-\mathrm{As}(\mathrm{V})$

mobilization and proved that UV irradiation could improve the immobilization of $\mathrm{As}(\mathrm{V})$ on $\mathrm{Sh}$ in aqueous environments including oxalate.
Acknowledgements This study was supported by the Science and Technology Plans of Tianjin (No. 15PTSYJC00230), Tianjin Research Program of Application Foundation and Advanced Technology (No. 17JCQNJC08000), and the National Natural Science Foundation of China (Nos. 41373114 and 41201487).

Open Access This article is distributed under the terms of the Creative Commons Attribution 4.0 International License (http://creativeco mmons.org/licenses/by/4.0/), which permits unrestricted use, distribution, and reproduction in any medium, provided you give appropriate credit to the original author(s) and the source, provide a link to the Creative Commons license, and indicate if changes were made.

\section{References}

1. Smedley PL, Kinniburgh DG (2002) A review of source, behaviour and distribution of arsenic in natural waters. Appl Geochem 17(5):517-568

2. Chen Y, Ahsan H (2004) Cancer burden from arsenic in drinking water in Bangladesh. Am J Public Health 94(5):741-744

3. Duker AA, Carranza EJM, Hale M (2005) Arsenic geochemistry and health. Environ Int 31(5):631-641

4. World Health Organization (1993) Guidelines for drinkingwater quality. Vol. 1: recommendations, 2nd edn. WHO, Geneva 
5. Mohan D, Pittman CU Jr (2007) Arsenic removal from water/ wastewater using adsorbents: a critical review. J Hazard Mater 142(1-2):1-53

6. Cornell RM, Schwertmann U (2003) The iron oxides: structure, properties, reactions, occurrences and uses. Wiley-VCH, Weinheim

7. Tufano KJ, Reyes C, Saltikov CW et al (2008) Reductive processes controlling arsenic retention: revealing the relative importance of iron and arsenic reduction. Environ Sci Technol 42(22):8283-8289

8. Sulzberger B, Laubscher H (1995) Reactivity of various types of iron(III) (hydr)oxides towards light-induced dissolution. Mar Chem 50(1-4):103-115

9. Borer PM, Sulzberger B, Reichard P et al (2005) Effect of siderophores on the light-induced dissolution of colloidal iron(III) (hydr)oxides. Mar Chem 93(2-4):179-193

10. Borer P, Kraemer SM, Sulzberger B et al (2009) Photodissolution of lepidocrocite $(\gamma-\mathrm{FeOOH})$ in the presence of desferrioxamine B and aerobactin. Geochim Cosmochim Acta 73(16):4673-4687

11. Banwart S, Davies S, Stumm W (1989) The role of oxalate in accelerating the reductive dissolution of hematite $\left(\alpha-\mathrm{Fe}_{2} \mathrm{O}_{3}\right)$ by ascorbate. Colloids Surf 39(2):303-309

12. Borer P, Sulzberger B, Hug SJ et al (2009) Photoreductive dissolution of iron(III) (hydr)oxides in the absence and presence of organic ligands: experimental studies and kinetic modeling. Environ Sci Technol 43(6): 1864-1870

13. Reichard PU, Kretzschmar R, Kraemer SM (2007) Dissolution mechanisms of goethite in the presence of siderophores and organic acids. Geochim Cosmochim Acta 71(23):5635-5650

14. Lan Q, Liu H, Li F et al (2011) Effect of $\mathrm{pH}$ on pentachlorophenol degradation in irradiation in irradiated iron/oxalate systems. Chem Eng J 168(3):1209-1216

15. Balmer ME, Sulzerger B (1999) Atrazine degradation in irradiated iron/oxalate systems: effects of $\mathrm{pH}$ and oxalate. Environ Sci Technol 33(14):2418-2424

16. Li FB, Li XZ, Liu CS et al (2007) Effect of oxalate on photodegradation of Bisphenol $\mathrm{A}$ at the interface of different iron oxides. Ind Eng Chem Res 46(3):781-787
17. Lei J, Liu C, Li F et al (2006) Photodegradation of orange I in the heterogeneous iron oxide-oxalate complex system under UVA irradiation. J Hazard Mater 137(2):1016-1024

18. Wu Y, Guo J, Jiang D et al (2012) Heterogeneous photocatalytic degradation of methyl orange in schwertmannite/oxalate suspension under UV irradiation. Environ Sci Pollut Res Int 19(6):2313-2320

19. Cheng H, Hu Y, Luo J et al (2009) Geochemical processes controlling fate and transport of arsenic in acid mine drainage (AMD) and natural systems. J Hazard Mater 165(1-3):13-26

20. Nordstrom DK, Alpers CN (1999) Negative pH, efflorescent mineralogy, and consequences for environmental restoration at the Iron Mountain Superfund site, California. Proc Natl Acad Sci USA 96(7):3455-3462

21. Jönsson J, Persson P, Sjöberg S et al (2005) Schwertmannite precipitated from acid mine drainage: phase transformation, sulphate release and surface properties. Appl Geochem 20(1):179-191

22. Regenspurg S, Brand A, Peiffer S (2004) Formation and stability of schwertmannite in acidic mining lakes. Geochim Cosmochim Acta 68(6):1185-1197

23. Song J, Jia SY, Ren HT et al (2015) Application of a high-surfacearea schwertmannite in the removal of arsenate and arsenite. Int J Environ Sci Technol 12(5):1559-1568

24. Zhang SL, Jia SY, Yu B et al (2016) Sulfidization of As(V)-containing schwertmannite and its impact on arsenic mobilization. Chem Geol 420:270-279

25. Loan M, Cowley JM, Hart R et al (2004) Evidence on the structure of synthetic schwertmannite. Am Mineral 89(11-12):1735-1742

26. Dhar RK, Zheng Y, Rubenstone J et al (2004) A rapid colorimetric method for measuring arsenic concentrations in groundwater. Anal Chim Acta 526(2):203-209

27. Stookey LL (1970) Ferrozine-a new spectrophotometric reagent for iron. Anal Chem 42(7):779-781

28. Jia Y, Xu L, Fang Z et al (2006) Observation of surface precipitation of arsenate on ferrihydrite. Environ Sci Technol 40(10):3248-3253 